\title{
Compulsory Hospitalization, Severity of Disorders and Territorial Landscape: A French Study
}

\author{
Jean-Luc Roelandt ${ }^{1,11}$, Aurore Crétin ${ }^{1,11}$, Françoise Askevis-Leherpeux ${ }^{1}$, Jean-Pierre Baucheron ${ }^{9}$, \\ Hélène Brun-Rousseau ${ }^{5}$, Magali Coldefy ${ }^{8}$, Véronique Daoud ${ }^{6}$, Laurent Defromont ${ }^{2}$, Jean-Yves Giordana ${ }^{7}$, \\ Isabelle Maillard ${ }^{1,12}$, Julie Roguet ${ }^{5,10}$, Hélène Saint-Jean ${ }^{1,2}$, Muriel Thalassinos ${ }^{6}$, Michel Triantafyllou ${ }^{4}$, \\ Stéphane Varomme ${ }^{2}$, Hélène Béhal ${ }^{3}$, Antoine Baleige ${ }^{1} \&$ Alain Duhamel $^{3}$ \\ ${ }^{1}$ WHOCC Lille, Lille, France \\ ${ }^{2}$ EPSM Lille-Métropole, Lille, France \\ ${ }^{3}$ Département de biostatistique, Centre Hospitalier Universitaire de Lille, Lille, France \\ ${ }^{4}$ CASH, Nanterre, Lille, France \\ ${ }^{5}$ AAPIMEP, Lille, France \\ ${ }^{6}$ Centre hospitalier Paul Guiraud Villejuif, Lille, France \\ ${ }^{7}$ Centre Hospitalier Sainte-Marie-Nice, Lille, France \\ ${ }^{8}$ IRDES, Lille, France \\ ${ }^{9}$ Centre Hospitalier Spécialisé Edouard Toulouse, Marseille, Lille, France \\ ${ }^{10}$ AAPIEMP, Centre Hospitalier de Cadillac, Lille, France \\ ${ }^{11}$ INSERM - ECEVE (UMR 1123 ), Lille, France \\ ${ }^{12}$ Université René Descartes, Lille, France \\ Correspondence: Jean-Luc Roelandt, WHOCC Lille, INSERM - ECEVE (UMR 1123), Lille, France. Tel: \\ 33-3-2043-7100. E-mail: jroelandt @epsm-lm.fr
}

Received: September 5, 2017 Accepted: October 18, 2017 Online Published: October 22, 2017

doi:10.5539/gjhs.v9n12p64

URL: https://doi.org/10.5539/gjhs.v9n12p64

The present study received financial support from different health authorities: the Direction Générale de l'Offre de Soins (PHRC 2010; 2012), the Direction Générale de la Santé et de la Fédération Régionale de Recherche en Santé Mentale, and the Agences Régionales de Santé (ARS) Ile de France and PACA.

It received approval from the following bodies concerned with individual privacy and freedom: the Comité de Protection des Personnes (CPP) Nord-Ouest IV, the Comite Consultatif sur le traitement de l'information en matière de Recherche dans le domaine de la Santé (CCTIRS), the Commission Nationale de l'Informatique et des Libertés (CNIL). This approval was confirmed after publication of Law $N^{\circ}$ 2111-803 of July 5th 2011.

\begin{abstract}
Introduction: The objective of this study, carried out in France, was to analyse important psychiatric sector disparities in the rate of compulsory hospitalizations as a function of the severity of disorders among the people hospitalized, and of certain variables linked to the territorial landscape (socio-demographic context, and primary and psychiatric care offer).
\end{abstract}

Methods: The 125 sectors that took part in this study were divided into three groups on the basis of their compulsory hospitalization rates.

Results: The results did not reveal any link between compulsory hospitalization rate and severity of disorders.

The hospitalization rate was correlated with variables specific to urban areas: it was higher in more densely populated areas with a larger proportion of people living alone and a greater number of shelters and social rehabilitation centres. It was also higher in the sectors with larger hospitalization capacity, with longer mean hospitalization durations, but with a lower rate of resort to psychiatry and larger human resources. 
Conclusions: The frequency of resort to involuntary hospitalization in France does not seem to be linked to the severity of patients' disorders, but it is higher in sectors with a profile specific to urban areas, larger hospitalization capacities and human resources.

Keywords: compulsory hospitalization, severity of disorders, territorial landscape, socio-demographic context, care offer

\section{Introduction}

The 1990 law governing compulsory hospitalizations in France was to be reviewed as from 1995. A report submitted in September 1997 (Rapport du groupe national d'évaluation de la loi du 27 juin 1990, in charge of evaluation of the legislation, $N^{\circ}$ 97081, September 1997) issued recommendations, but not all of them were taken up by the authorities. In 2001, a report by Piel \& Roelandt (De la psychiatrie vers la santé mentale), submitted to the health minister, raised the issue of the "French exception": the Prefect, or the local state representative, was the person who, at once orders and checks commitments, known as "hospitalisations d'office" or compulsory hospitalizations, and was in charge of commitments requested by third parties, mainly by families, which is called "hospitalisation à la demande d'un tiers" (hospitalisation on request from a third party). For reasons of power-sharing, the authors of this report thought that judges - and not the administrative authorities should have the decision to coerce people with mental disorders into treatment. This proposal was only enforced by law in 2011, when a citizen appealed to the Constitutional Council, which then issued a decision in favour of judiciary rulings.

Between these two periods, in 2004, a tragic event took place in Pau. A patient suffering from addiction and psychotic disorder left the hospital, later came back in the middle of the night and killed a nurse and an auxiliary nurse after breaking into one of the wings. As a result, emphasis was put on security aspects in psychiatry, stressing the potential dangerousness of mentally ill patients. Dangerousness is a subjective perception, dependent on the requirements of Criminal Law and on people's expectations in terms of safety and protection. The Haute Autorité de Santé (health authority [HAS], 2011) stresses that dangerousness is generally considered as a potential for violence, so that its definition depends on how violence is defined. For instance, the WHO gives a broad definition of violence, as "the intentional use of physical force or power, threatened or actual, against oneself, another person, or against a group or community that either results in or has a high likelihood of resulting in injury, death, psychological harm, mal-development or deprivation" (Krug, Dahlberg, Mercy, Zwi, \& Lozano-Ascencio, 2002).

In France, the possible dangerousness of psychiatric patients became a central issue in political and healthcare debates in the area of mental health. In 2007, the Association Française de Psychiatrie (French psychiatric association) defined psychiatric dangerousness as a manifestation of symptoms related to a direct expression of mental illness. Thus, whatever the nature of the situation leading to a danger, the "mental patient" is liable to carry this danger within him, as if the dangerousness was inherent in the person. This resulted in more security-oriented policies.

This period was indeed marked by the reinforcement of hospital-centred strategies, the building of walls and fences and the closing of some units in psychiatric departments. The 2005-2008 mental health plan invested more than 1.5 billion euros in the reconstruction of hospitals and important funds in security measures (isolation rooms, fences, alarms, etc....).

In 2008, security was reinforced once again, following the murder of a young man in Grenoble by a patient who had been granted leave of absence. Psychiatrists were asked to toughen the supervision of people who were thought to be dangerous as well as their involuntary commitment conditions, by setting priorities on building walls and security rather than on integration into the community. This fact is all the more important to mention because the organization of public psychiatry into different sectors, free care, prevention and rehabilitation, were supposed to decrease the frequency of compulsory commitments, enable access to early treatment and support the patients in their plans for life.

A study from the Direction Générale de la Santé (General health administration, [DGS]) in 2007 reported that compulsory hospitalization rate varied from 1 to 10 between départements (French administrative areas), while psychiatric epidemiology on its own could not justify this variation.

In addition, given the changes to be made in the 2011 law, a study on compulsory hospitalizations proved necessary to try and understand this situation and identify some of the factors that influence the resort to hospitalizations without consent.

It is in this context that the French WHO Collaborating Centre (WHOCC), in collaboration with three 
associations (Note 1), decided to undertake research on compulsory) hospitalizations decided by state representatives.

\subsection{Hospitalization without Consent}

In France, compulsory hospitalizations have been governed by different laws since 1838. At that time, it was called "placement d'office" (compulsory admission). Generally, a provisional decision was made by the Major and then formalised by the Prefect (state representative in each département). Medical opinion was optional and not part of the law (Trojak, 2006). The aim of this type of placement was to preserve public order and people's security.

The law of $27^{\text {th }}$ June 1990 in the French Code de Santé Publique (Public health code [CSP]) aimed to reinforce the rights of hospitalized patients. It clearly defined rules of hospitalization in psychiatry according to three modes: voluntary hospitalization ( $\mathrm{VH}$ ), and two types of hospitalization without consent (HWC): hospitalisation on request from a third party (HRTP) and compulsory hospitalization, made on the request of a state representative $(\mathrm{CH})$. The breakthrough of this law was to restrict hospitalizations without consent to hospitalizations proved necessary by the person's state of health and by the instatement of treatment (article L3212-2 of the French public health code).

HRTP can be decided only if the person concerned shows signs of a mental disorder requiring treatment, and if the nature of this disorder prevents him/her from giving his/her consent. $\mathrm{CH}$, on the other hand, can only occur if the person disrupts public order and/or jeopardizes people's safety (article L.3212-1). A medical certificate testifying the presence of these conditions is compulsory.

The 1990 law stipulated two procedures for $\mathrm{CH}$ : the usual procedure and an emergency procedure. The first is carried out on order of the Prefect on the basis of a detailed medical certificate testifying the necessary conditions for $\mathrm{CH}$. In the second procedure, these conditions are attested by the Mayor, on the basis of simple written medical opinion, or otherwise on the basis of "public notoriety". A prefectoral decision is then pronounced (or not) within 24 hours. This issue of consent does not appear in the law.

The law of $4^{\text {th }}$ March 2002 restricted the $\mathrm{CH}$ procedure to patients whose disorder required treatment and "seriously" disrupted public order and/or jeopardized people's safety (article L.3213-1). The first of these conditions reinforced the need for medical opinion. (Note 2)

And finally, the law of $5^{\text {th }}$ July 2011, in addition to the reinforcement of patients' rights, amended the terminology. The term "hospitalisation d'office" (compulsory hospitalisation, $\mathrm{CH}$ ) was thus changed to "soins psychiatriques sur décision du représentant de l'état" (psychiatric treatment on decision by the state representative). It allows a wider care provision, especially in ambulatory care. This law also provides for a systematic validation of hospitalizations by what are known as "liberty and custody" judges within fifteen days, reduced to twelve days since 2013 (Note 3).

Because the judges' power has been systemized, the initial legislative model, based on administrative power, has been transformed into a mixed system, an administrative system for admissions and a judiciary system for validation. This amendment aligned the French model on other European models, which are mainly mixed or in some cases only judiciary.

\subsection{The Situation in France (Table 1)}

In France the hospitalization rate in psychiatry rose more than 82\% from 1989 to 2007 (Coldefy \& Salines, 2004). In 2007, 72598 hospitalizations without consent were declared, representing $12 \%$ of the total number of hospitalizations in psychiatry, and corresponding mainly to hospitalizations on request of a third party (Note 4).

Table 1. Involuntary Hospitalisations: evolution 2007 to 2010 in numbers of hospital stays

\begin{tabular}{llll}
\hline & Compulsory hosp. & Hosp. on request from third party & Total \\
\hline 2007 & $9438(13 \%)$ & $63160(87 \%)$ & 72598 \\
2010 & $19496(20 \%)$ & $76733(80 \%)$ & 96227 \\
\hline
\end{tabular}

Sources: DGS, CDHP activity reports (2007), ATIH (2010).

In 2010, hospitalizations without consent (HWC) in general continued to increase, with 96227 HWCs decided in France (16.07\% of all hospitalizations in psychiatry), an increase of $34 \%$ compared to 2007 (Table 1). At the 
same time, among HWCs, the proportion of CH increased from 13\% to 20.26\% (19 496 IHs) (Note 5).

\subsection{Territorial Variability: from the French Département to the Sector (Figure 1)}

The $\mathrm{CH}$ rate varies greatly from one département to the next (by a factor of 14 in 2000; 9.8 in 2007). For instance, in 2007, the rate for 100000 inhabitants aged 20 and over was 49 per 100,000 in the Haute-Vienne département against 5 per 100000 in the Nord and the Landes départements (source: Local commissions for psychiatric hospitalizations)

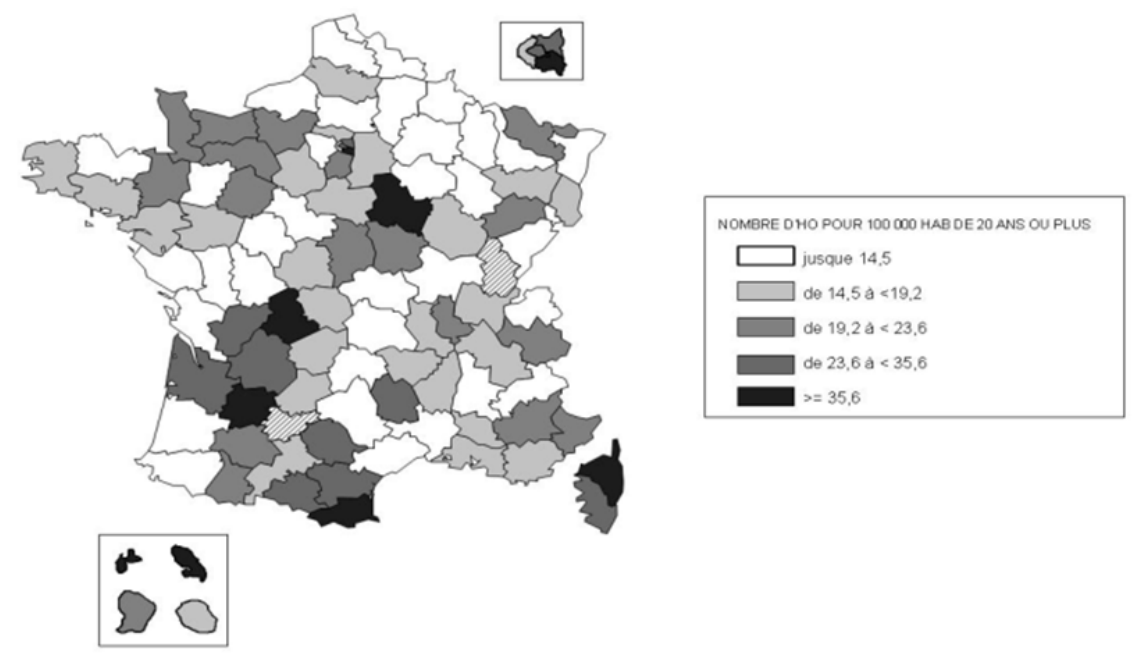

Figure 1. Rate of compulsory hospitalisations per 100000 inhabitants by département

However, it is not on the level of the French départements that care is organised but of sectors. The $15^{\text {th }}$ March 1960 circular defined a care sector as a geo-demographic area delineated by 67000 inhabitants, with the aim of providing care for people as early as possible, treating them as close as possible to their family and surroundings, ensuring continuity of care from prevention to post-cure, and following-up with a multidisciplinary team headed by a psychiatrist.

From 1968, psychiatric care was also organized into different sectors. In 2009, according to the Agence Technique d'Information sur les Hospitalisations (French agency for hospital information processing [ATIH]), there were 815 adult psychiatric sectors. However, the variability of involuntary hospitalizations across départements also applied to the sectors, ranging from 0 to 54 per 100000 inhabitants on the same date.

This is why we chose the psychiatric sector as the geographical unit, especially as psychiatric sectors vary in terms of means (Alluard \& Coldefy, 2002; Coldefy \& Bousquet, 2002) and care provision (Coldefy, Le Fur, Lucas-Gabrielli, \& Mousquès, 2009).

\subsection{Objectives}

This disparity across sectors raises the issue of its determining factors. Indeed, a better understanding of the mechanisms of compulsory hospitalizations would enable better prevention of this sort of hospitalization and would allow other types of care to be considered, such voluntary and/or ambulatory hospitalizations, or prevention by means of continued care.

Our objective was to determine whether these disparities were linked to certain factors identified as having a role in the resort to compulsory admissions, in particular, the severity of disorders among the people hospitalized and the territorial context in terms of socio-demographic characteristics and the care offer.

\subsubsection{The patient and his/her pathology: severity of disorders}

The decision to resort to hospitalizations without consent concerns the whole range of psychological disorders, but is more frequent in the case of schizophrenia, and personality and behavioural disorders (Jaeger et al., 2013; Rusch et al., 2014; Van der Post et al., 2008; Wheeler, Robinson, \& Robinson, 2005). The same observation is 
made on territorial level and in cases of long-term hospitalizations (Coldefy \& Nestrigue, 2010).

\subsubsection{Territorial Landscape}

\subsubsection{Demography of the Territory}

Certain socio-demographic factors, such as isolation, gender, age, education, origin, home location, or income, have an influence on the rate of compulsory hospitalizations

(Hustoft, Larsen, Auestad, Joa, Johannessen, \& Ruud, 2013; Rosca, Bauer, Grinshpoon, Khawaled, Mester, \& Ponizovsky, 2006; Weich et al., 2014). Similarly, socio-economic deprivation and being faced with unemployment favour resort to hospitalizations without consent (Bindman, Tighe, Thornicroft, \& Leese, 2002; Guzzetta et al., 2010; Vand der Post et al., 2008). A recent study carried out in France (Coldefy, Nestrigue, Younès, \& Paget, 2106) has revealed the specific role that social fragmentation plays (weakness of social ties) in the resort to hospitalizations without consent, that is to say, on the request from a state representative, the family or a third party.

\subsubsection{The Care Offer}

Sectors differ in terms of care offer in psychiatry, especially concerning the allocation of equipment and staff, the nature of treatment and service offer and the patterns of resort to treatment (Coldefy \& Bousquet, 2002; Joubert, Hechinger, Chevallier, \& Marescaux, 2016).

In conclusion, the objective was to determine if sectorial variability in compulsory hospitalizations corresponded to a sectorial variability in the severity of the disorders for patients hospitalized in this way, or to a sectorial variability in certain aspects of the territorial landscape (the socio-demographic context and the care offer).

\section{Method}

The study took place from October 2009 to July 2012.

\subsection{Three Sector Groups}

Following an information pack and an invitation addressed to all the sectors from 4 regions (Nord-Pas de Calais, Ile de France, Aquitaine and Provence-Alpes-Côte d'Azur), 125 psychiatry sectors took part in the study on a voluntary basis: 28 in Nord-Pas de Calais, 42 in Ile de France, 22 in Aquitaine and 33 in Provence-Alpes-Côte d'Azur. These sectors, representing in all $15 \%$ of the total number of sectors listed by the ATIH, were under the authority of either psychiatric hospitals or psychiatric units in general hospitals.

For each sector, for the inclusion year, we calculated the rate of involuntary hospitalizations, i.e. the number of hospitalizations for 100000 inhabitants aged 18 and over. These rates were checked via the legal registers of French hospitals taking in persons committed to receive treatment, and/or via the hospital medical information services. Concerning sectors that carried out inclusions over two years, the mean rates of these two years was calculated.

In order to identify homogenous sector groups in terms of involuntary hospitalizations, an ascending hierarchic classification was carried out (Ward's method), thus minimizing intra-class differences whilst at the same time optimizing interclass differences. The analysis led to the formation of three groups:

Sectors with a low rate $(n=41)$ : rate per 100000 inhabitants below 8.5 .

Sectors with a medium rate $(\mathrm{n}=60)$ : rate per 100000 inhabitants between 8.5 and 22 .

Sectors with a high rate $(\mathrm{n}=24)$ : rate per 100000 inhabitants over 22 .

2.2 Severity of Disorders: the Global Assessment Scale - GAS- (Endicott, Spitzer, Fleiss, \& Cohen, 1976)

The Global Assessment Scale enables an evaluation of the psychological, social and professional functioning of a person, on a hypothetical continuum from 0 (non-existent functioning, similar to death) to 100 (perfect functioning in all aspects, one of which is optimal mental health), scoring functioning for all three domains. It can be noted that this assessment has been evaluated as being very sensitive to clinical states (Workin et al., 1990).

The GAS evaluation was carried out on the basis of 24-hour medical certificates, used for the decision to hospitalise. These certificates, mentioning at least the symptoms and the potential dangerousness of the patients, are rendered anonymous by the teams in the psychiatry sectors, and issued without last names, first names, addresses, entry dates or the name of the certifying doctor. The only piece of information kept is the number of the psychiatry sector the patient is attached to. 
All certificates were evaluated by just one assessor, a psychologist, trained to use the tool, and for whom a preliminary phase confirmed the reliability of the coding (Note 6).

A GAS score was calculated for the 24-hour certificates concerning involuntary hospitalizations that took place in the sectors taking part in the study between February 2009 and July 2012. These 24-hour certificates concerned any person having been hospitalized or treated by order of a state representative (triggered by order of the prefect or by a temporary order from the Mayor), whatever their sector of origin, and including homeless people. The certificates for people managed by the prison services (Note 7), and for those who received a dismissal of the charges for criminal offense for reasons of mental health, (Note 8), with a low rate of involuntary hospitalizations/psychiatric treatment on the decision of a state representative, 582 for sectors with a medium rate and 418 for sectors with a high rate.

\subsection{Territorial Context: Demography and Care offer}

In order to characterize territories in terms of socio-demographic environment and care offer, a list of 77 variables, potentially explaining the variability of the $\mathrm{CH}$ rate (Appendix 1), dichotomous, frequency, or quantitative, were collected and broken down into three categories.

\subsubsection{Demography}

- Socio-demographic data (e.g. total population, unemployment rate)

- Description of the sectorial (e.g. surface area of the sector) and judiciary (e.g. presence of a prison) territories

\subsubsection{Care Offer}

Care offer in general medicine

- Description of "files actives" (i.e. the patients seen at least once in the year) and hospital stays (e.g. average length of hospitalization)

- Institutions, facilities, units (e.g. presence of an emergency reception facility)

- Human resources (e.g. density of general practitioners)

Care offer in psychiatry

- Description of "files actives" (i.e. the numbers of patients seen at least once in psychiatry facilities in the year) and hospital stays (e.g. average length of hospitalization)

- Institutions, facilities, units (e.g. density of specialized beds)

- Human resources (e.g. density of psychiatrists)

\section{Results}

The results were processed using SAS software version 9.3 (from the SAS Institute - CARY NC - USA).

\subsection{The Severity of the Disorders}

The average GAS scores (and the standard deviations) for the three groups were respectively 29.41 (18.94) for the low rate group, 28.03 (17.06) for the intermediate group, and 27.14 (15.25) for the high rate group.

The analysis of variance, using a mixed model, with the sectors as a random factor, did not reveal any differences across the three groups, $F(2,1022)=0.67, p>.50$, suggesting that there was no link between $\mathrm{CH}$ rate and severity of disorders.

\subsection{Territorial Context: Demography and Care Offer}

The quantitative variables at sector level were compared between groups using Kruskal Wallis analysis of variance.

Categorical variables were subjected to Chi-squared tests, crossing compulsory hospitalization rate with the different variables.

Only results that were significant at a threshold of 0.05 or below $(n=20)$ were retained.

For all significant variables, analyses were completed using two-by-two comparisons. The results (see Tables 2

\& 3) revealed that, while the extreme groups still differed, the sectors with an average rate were very often equivalent to those with a low rate. In addition, for each variable category, we calculated correlations between variables linked to the hospitalization rate (Spearman's rho, $p<.05$ ). 


\subsubsection{Demography: Socio-Demographic Data and Territory Description (Table 2)}

Table 2. Territorial landscape (1). Median (and interquartile interval) of the social demographic variables linked to the sectorial rate of compulsory hospitalizations $(\mathrm{p}<.05)$

\begin{tabular}{|c|c|c|c|c|c|}
\hline & \multicolumn{4}{|c|}{ Sectorial rate of hospitalizations } & \multirow[b]{2}{*}{$p$} \\
\hline & $\begin{array}{l}\text { Global } \\
\mathrm{n}=120\end{array}$ & $\begin{array}{l}\text { Low } \\
\mathrm{n}=41\end{array}$ & $\begin{array}{l}\text { Medium } \\
\mathrm{n}=60\end{array}$ & $\begin{array}{l}\text { High } \\
\mathrm{n}=19\end{array}$ & \\
\hline $\begin{array}{l}\text { Sociodemographic data } \\
\text { Proportion in \% of isolated people }\end{array}$ & $\begin{array}{l}13 \\
(5.50)\end{array}$ & $\begin{array}{l}11_{\mathrm{a}} \\
(4)\end{array}$ & $\begin{array}{l}12.50_{\mathrm{ab}} \\
(5.50)\end{array}$ & $\begin{array}{l}16_{c} \\
(7)\end{array}$ & $<.05$ \\
\hline \multicolumn{6}{|l|}{ Description of the psychiatric territory } \\
\hline $\begin{array}{l}\text { Surface area of the general psychiatry sector } \\
\left(\text { in } \mathrm{km}^{2}\right)\end{array}$ & $\begin{array}{l}110 \\
(498.50)\end{array}$ & $\begin{array}{l}128_{\mathrm{ab}} \\
(305)\end{array}$ & $\begin{array}{l}88 b_{a} \\
(586.50)\end{array}$ & $\begin{array}{l}8_{\mathrm{ac}} \\
(1237)\end{array}$ & $<.01$ \\
\hline $\begin{array}{l}\text { Mean distance weighted by the population to } \\
\text { the nearest unit for difficult patients (in min) }\end{array}$ & $\begin{array}{l}103.50 \\
(107.5)\end{array}$ & $\begin{array}{l}142_{\mathrm{a}} \\
(72)\end{array}$ & $\begin{array}{l}99.50_{\mathrm{b}} \\
(107.50)\end{array}$ & $\begin{array}{l}39 \mathrm{c} \\
(16)\end{array}$ & $<.001$ \\
\hline \multicolumn{6}{|l|}{ Description of the judiciary territory } \\
\hline $\begin{array}{l}\text { Mean distance to the nearest police station (in } \\
\min \text { ) }\end{array}$ & $\begin{array}{l}3 \\
(4)\end{array}$ & $\begin{array}{l}4 a \\
(2)\end{array}$ & $\begin{array}{l}3 \mathrm{a} \\
(4)\end{array}$ & $\begin{array}{l}1_{b} \\
(4)\end{array}$ & $<.05$ \\
\hline $\begin{array}{l}\text { Mean distance to the nearest département } \\
\text { Préfecture (in min) }\end{array}$ & $\begin{array}{l}29 \\
(24.50)\end{array}$ & $\begin{array}{l}32_{\mathrm{a}} \\
(27)\end{array}$ & $\begin{array}{l}28_{\mathrm{b}} \\
(27.50)\end{array}$ & $\begin{array}{l}19_{\mathrm{b}} \\
(8)\end{array}$ & $<.01$ \\
\hline
\end{tabular}

Note. Medians in the same row that do not share at least one subscript differ at $\mathrm{p}<.05$.

Compared to sectors with an average and/or low compulsory hospitalization rate, sectors with a high rate were characterized by a higher proportion of the 18-64 age range, a higher proportion of working people in that age bracket and a globally higher proportion of isolated people.

These sectors correspond to psychiatry sectors with a smaller surface area, characterized by a shorter distance to the nearest unit "for difficult patients", the two variables being correlated, $r h o(118)=+.38, p<.001$. The sectors with a high rate also have a higher proportion of local mental health Councils, $\chi^{2}(2)=10.16, p<.001$. They also have more shelters and social rehabilitation centres, $\chi^{2}(2)=6.5, p<.05$. None of the two-by-two comparisons was significant (Note 9). The same trend can be observed if the Nord-Pas de Calais region, in which there are no units for difficult patients, is excluded.

In addition, the mean distance to the nearest police station or the département Prefecture was smaller in sectors with a high involuntary hospitalization rate than in any other type of sector.

Finally, the correlation analyses revealed that these two distance variables correlated positively with each other, rho $(118)=+.31, p<.001$, and with the surface area, rho $(118)=+.28$ and $+.49, p<.001$. However, each one of them correlated negatively with the proportion of isolated people, respectively rho (118) $=-.37,-.47$ and $.26, p$ $<.001$. There appear therefore to be fewer isolated people in sparser urban areas.

\subsubsection{Care offer}

Only the variables concerning psychiatric treatment provision were linked to the compulsory hospitalization rate (Table 3). 
Table 3. Territorial landscape (2): Median (and interquartile interval) of treatment provision variables in psychiatry linked to the sectorial rate of compulsory hospitalizations $(\mathrm{p}<.05)$

\begin{tabular}{|c|c|c|c|c|c|}
\hline \multicolumn{6}{|c|}{ Sectorial rate of hospitalization } \\
\hline & $\begin{array}{l}\text { Global } \\
\mathrm{n}=120\end{array}$ & $\begin{array}{l}\text { Low } \\
\mathrm{n}=41\end{array}$ & $\begin{array}{l}\text { Medium } \\
\mathrm{n}=60\end{array}$ & $\begin{array}{l}\text { High } \\
\mathrm{n}=19\end{array}$ & $p$ \\
\hline \multicolumn{6}{|l|}{ Active file } \\
\hline $\begin{array}{l}\text { Proportion of patients examined at least once a } \\
\text { year for } 100000 \text { inhabitants }\end{array}$ & $\begin{array}{l}1945 \\
(844.5)\end{array}$ & $\begin{array}{l}2386_{\mathrm{ab}} \\
(856)\end{array}$ & $\begin{array}{l}1885_{\mathrm{a}} \\
(745)\end{array}$ & $\begin{array}{l}1788_{\mathrm{ac}} \\
(685)\end{array}$ & $<.01$ \\
\hline $\begin{array}{l}\text { Proportion of patients examined at least once a } \\
\text { year by a psychiatrist in general psychiatry for } \\
100000 \text { inhabitants }\end{array}$ & $\begin{array}{l}360.32 \\
(282.32)\end{array}$ & $\begin{array}{l}405.28 \mathrm{a} \\
(209.56)\end{array}$ & $\begin{array}{l}360.79_{\mathrm{ab}} \\
(263.35)\end{array}$ & $\begin{array}{l}215.54 \mathrm{ac} \\
(54.65)\end{array}$ & $<.01$ \\
\hline $\begin{array}{l}\text { Proportion of patients examined at least once a } \\
\text { year in ambulatory psychiatric care exclusively } \\
\text { for } 100000 \text { inhabitants }\end{array}$ & $\begin{array}{l}1652 \\
(648)\end{array}$ & $\begin{array}{l}1776_{\mathrm{ab}} \\
(284)\end{array}$ & $\begin{array}{l}1630.5 \mathrm{a} \\
(515)\end{array}$ & $\begin{array}{l}1180_{c} \\
(350)\end{array}$ & $<.01$ \\
\hline \multicolumn{6}{|l|}{ Hospital beds and hospital stay } \\
\hline $\begin{array}{l}\text { Density of full-time hospitalization beds in } \\
\text { specialized psychiatry units located in } \\
\text { communes of a mega-sector for } 100000 \\
\text { inhabitants }\end{array}$ & 41 & $\begin{array}{l}27_{\mathrm{ab}} \\
(89)\end{array}$ & $\begin{array}{l}41_{\mathrm{a}} \\
(96)\end{array}$ & $\begin{array}{l}86_{\mathrm{ac}} \\
(185)\end{array}$ & $<.05$ \\
\hline Rate of bed use & $\begin{array}{l}88 \\
(9)\end{array}$ & $\begin{array}{l}85_{\mathrm{a}} \\
(10)\end{array}$ & $\begin{array}{l}91,50_{\mathrm{b}} \\
(8)\end{array}$ & $\begin{array}{l}92_{\mathrm{bc}} \\
(11)\end{array}$ & $<.001$ \\
\hline $\begin{array}{l}\text { Average duration of hospitalization in } \\
\text { psychiatry (in days) }\end{array}$ & 42 & $\begin{array}{l}36 \mathrm{ab} \\
(10)\end{array}$ & $\begin{array}{l}43 \mathrm{a} \\
(12)\end{array}$ & $\begin{array}{l}58_{\mathrm{ac}} \\
(26)\end{array}$ & $<.001$ \\
\hline \multicolumn{6}{|l|}{ Staff } \\
\hline $\begin{array}{l}\text { Density of psychiatrists employed in general } \\
\text { psychiatry (equivalent to full-time) for } 100 \\
000 \text { habitants }\end{array}$ & $\begin{array}{l}8 \\
(4)\end{array}$ & $\begin{array}{l}7 \mathrm{a} \\
(1)\end{array}$ & $\begin{array}{l}7 \mathrm{a} \\
(4)\end{array}$ & $\begin{array}{l}11_{\mathrm{b}} \\
(7)\end{array}$ & $<.001$ \\
\hline $\begin{array}{l}\text { Equivalent full-time } \\
\text { (full-time) }\end{array}$ & $\begin{array}{l}50.84 \\
(32.77)\end{array}$ & $\begin{array}{l}43.08_{a} \\
(21.61)\end{array}$ & $\begin{array}{l}49.91_{\mathrm{a}} \\
(33.48)\end{array}$ & $\begin{array}{l}78.60_{\mathrm{b}} \\
(36.53)\end{array}$ & $<.001$ \\
\hline Equivalent full-time (not including full-time) & $\begin{array}{l}28,31 \\
(20.20)\end{array}$ & $\begin{array}{l}24.75_{a} \\
(24.21)\end{array}$ & $\begin{array}{l}27.65 \mathrm{a} \\
(15.10)\end{array}$ & $\begin{array}{l}32.20_{\mathrm{b}} \\
(29.81)\end{array}$ & $<.001$ \\
\hline Total number of equivalent full-time & $\begin{array}{l}79.46 \\
(49.62)\end{array}$ & $\begin{array}{l}70_{\mathrm{a}} \\
(39.52)\end{array}$ & $\begin{array}{l}77.75_{\mathrm{a}} \\
(49.74)\end{array}$ & $\begin{array}{l}110.80_{\mathrm{b}} \\
(78.59)\end{array}$ & $<.001$ \\
\hline
\end{tabular}

Note. Medians in the same row that do not share at least one subscript differ at $\mathrm{p}<.05$.

\subsubsection{Active File}

The results first revealed that the sectors with a high IH rate are characterized by smaller numbers of patients in the "files actives" i.e. fewer patients examined at least once in the year by a psychiatrist or seen in ambulatory care. These three variables are linked one to another, respectively rho $(118)=+.60,+.80$ and +53 , all $p<.001$.

\subsubsection{Hospital Beds and Hospital Stay}

The results also revealed that the sectors with a high IH rate have a higher density of beds than the sectors with an average or a low rate.

The occupation rate of these beds is not linked to any of these variables. It seems independent from the density of the use of beds full-time and from the duration of full-time hospitalizations. 


\subsubsection{Staff}

The sectors with a high compulsory hospitalization rate have more substantial hospital staff in their full-time or part-time (part-time or ambulatory care) hospitalization services and a higher density of salaried psychiatrists. The correlational analysis revealed that these variables correlated with one another, respectively rho (118) $=.89, .49$ and .83 , all $p<.001$.

\section{Discussion}

The objective of this study was to examine the disparity across sectors of compulsory hospitalization rate and to analyse any links with the severity of the disorders of the patients hospitalized in that way and with certain territorial variables concerning the sector (demography and care offer).

The results did not reveal any links with the severity of the disorders, but demonstrated the considerable role of the territorial psychiatric landscape, in particular care offer organisation. The results suggest that sectors with a high rate of $\mathrm{CH}$ do not enlist people with milder disorders. This could suggest that other modes of care and prevention are available and applied, or again that people are less isolated and have greater social support.

Overall, compared to the other types of sector, sectors with a high $\mathrm{CH}$ rate have a smaller surface area, and are closer to a police station or a Prefecture. They have a larger proportion of people living alone and they possess more local health Councils or at least one accommodation and social rehabilitation facility. All these characteristics are typical of urban areas. These elements have been reported throughout the literature (Coldefy \& Nestrigue, 2014).

The psychiatric care offer, and not the general medicine one, also seems to play an important role. Sectors with a high $\mathrm{CH}$ rate have a larger capacity for full-time hospitalizations in specialized public institutions (public or private). The average hospitalization duration is longer, whereas the rate of resort to psychiatry in a public health facility is lower. The numbers of medical and nursing staff are larger, the average density of patients per psychiatrist is lower and the units for difficult patients are nearer. Sectors with a high $\mathrm{CH}$ rate are better provided than the others, as much in terms of hospitalization capacity as of human resources.

To sum up, sectors with a high $\mathrm{CH}$ rate are characterized by a high rate of isolated people and more facilities, such as shelters and social rehabilitation centres. Several studies have demonstrated the role of isolation and precariousness in the resort to psychiatric hospitalization without consent. Although the care offer in these sectors seems quite substantial in terms of human resources and hospitalization capacity, it is nevertheless centred on hospitalization, with a higher average duration of hospital stay and a lower resort rate in ambulatory care in particular, despite the development and growing numbers of extra-hospital staff. This is in line with recent French studies showing that the length of stay in full time hospitalisation and the rate of involuntary full-time admissions are negatively associated with the development of alternative care (Gandré, Gervaix, Thillard, Macé, Roelandt, \& Chevreul, 2017a; 2017b).

The more frequent allocation to specialized centres with a larger hospitalization capacity can partly be explained by the fact that these centres have always had greater means than those implanted in general hospitals. The greater proximity with police stations and the Prefecture for their part appears to be more related to the urban nature of the sectors involved, rather than to behaviours that are differentiated by these proximity factors.

Conversely, sectors with a low $\mathrm{CH}$ rate have a higher ambulatory activity, reduced hospitalization stays and a lower density of beds, and psychiatrists see twice as many patients at least once in the year as in sectors with a higher rate. One interesting aspect is that the rate of hospital bed occupation is lower, suggesting that practices are less centred on hospitalization and more on prevention.

It could be argued that one limitation of this study was that it was based on voluntary participation. There is no evidence to support that volunteering sectors are representative of their region or that they resemble other sectors that have the same rate (low, medium or high) of compulsory hospitalizations. In fact, some sectors with a high rate refused this survey. Nevertheless, to form the sample, it was sectors with a low rate that were particularly lacking in order to reach the statistical numbers required, and there is no evidence to suggest that voluntary participation led to a bias on the results. Besides, the large number of sectors, unparalleled in French literature, probably compensates for any potential bias.

As a conclusion, sectors varying in terms of compulsory hospitalization rates differ on certain variables linked to socio-demographic contexts and to care offer, while this rate is not linked to the severity of the disorders.

However, it is possible that the diversity of socio-demographic contexts and the care offer is the reflection of differences in local health practices or in the information available to decision-makers (Emons et al., 2014). 
Taking these aspects into consideration will enable a better understanding of the mechanisms of compulsory hospitalization and suggest alternative care that will certainly involve alteration of usual practices.

\section{Competing Interests Statement}

The authors declare that there are no competing or potential conflicts of interest.

\section{Acknowledgements}

We would like to thank the directors and the staff of the medical information centres who have participated in the study and ensured its smooth progress

Agnès Vallet-Anfosso, CH d'Antibes Juan Les Pins

Ariski Taleb, Xavier Lamour CH Montreuil

ARS Ile de France

ARS Provence-Alpes-Côte-D'azur

Awa Baradgi CH Mont de Marsan

Bénédicte Soula $\mathrm{CH}$ des Pyrénnées

Blanc Juliette, CH Henri-Guerin-Var/Pierrefeu

Carole Marrazo, CH Edouard Toulouse

Christian Porteaux $\uparrow$ EPSM Lille Métropole

Christine Buchatz, Oliver Embs, Duc-Tinh Nguyen Etablissement public de santé ERASME

Christine Lescun, François Dechabalier, Bérénice Brechat CH Cadillac

Corinne Kamoise, Cécile Omnes, Cécile Crozier EPS Charcot

Dominique Desse, $\mathrm{CH}$ de Grasse

Dominique Malet Pinsolle CH de Dax

Fabienne Coquelet, Nadia Hazzem CHRU Lille

Françoise Huet, Séverine Moulin Philippe Fornari CH de Montperrin

Gilles Desmaison, CH Vauclaire

Hippolyte Digbeu Ch Lagny Marne la Vallée et Ch de Meaux

Isabelle Blanchard $\mathrm{CH}$ de la Côte Basque

Jean Oureib EPSM Agglomération Lilloise

Jean-Pierre Pellegrini, CH d'Arles

Jérôme Sicot, $\mathrm{CH}$ de Boulogne sur mer

Kankoé Amah-Tchoutchoui CH de Douai et EPSM des Flandres

Laurent Boyer, APHM Sainte-Marguerite

Lisiane Lagache, Jacques Louvrier, Isabelle Bongo CH Hénin- Beaumont

Marie Claire Bouny, Vincent Leroux Les hôpitaux de Saint-Maurice Esquirol

Marie-Anne Guichard, Annie Durieux, CH BuëchDurance Laragne

Marie-Christine Nuttens CH de Douai

Marie-Rose Saintaraille Les hôpitaux de santé Perray-Vaucluse/Henry Ey

Michel Degroisse Ch de Denain

Nadine Fumery, Bruno Pequignot, EPSM Val de lys

Nathalie Richardet, Mohamed Bentolba Marcel Nguefack CASH de Nanterre

Philippe Dunezat, CHS Sainte Marie Nice

Pierre Alziar, CH de Digne

Pierre Leblond, Zahia Djenati Ch Sambre Avesnois Maubeuge

Pierre-Luc Geniller, Claude Peynaud, CH de Cannes 
Richard Soidet, $\mathrm{CH}$ de Montfavet

Serge Groshens $\mathrm{CH}$ de Pontoise

Stéphanie Paty, Alain Lepla CH de Cambrai

Thierry Guérout Ch Les Murets

Valérie Le Masson CH Sainte-Anne

Véronique Buhaj CH Périgueux

Véronique De La Fournière, $\mathrm{CH}$ de Martigues

Véronique Wesolek, Claude Langlet, $\mathrm{CH}$ de Somain

Yann Le Dosseur EPS Ville-Evrard

Yves Gendreike, Claire Bourdais-Mannone CHU Pasteur Nice

\section{References}

Alluard, O., \& Coldefy, M. (2005). Atlas régional de psychiatrie générale. Disparités de l'offre et des territoires d'intervention. Drees, Document de travail, série Etudes, n75, février.

Bindman, J., Tighe, J., Thornicroft, G., \& Leese, M., (2002). Poverty, poor services, and compulsory psychiatric admission in England. Social Psychiatry and Psychiatric Epidemiology, 37, 341-345. https://doi.org/10.1007/s00127-002-0558-3

Coldefy, M., \& Bousquet, F. (2002). Une typologie des secteurs de psychiatrie générale en 1999, Drees, Etudes et Résultats.

Coldefy, M., Le Fur, P., Lucas-Gabrielli, V., \& Mousquès, J. (2009). Cinquante ans de sectorisation psychiatrique en France: des inégalités persistantes de moyens et d'organisation. Questions d'Economie de la Santé, 145, $1-8$.

Coldefy, M., \& Nestrigue, C. (2014). L'hospitalisation au long cours en psychiatrie : analyse et déterminants de la variabilité territoriale. Questions d'économie de la Santé, $n^{\circ} 202$, octobre.

Coldefy, M., Nestrigue, C., Younès, N., \& Paget, L. M. (2016). L'hospitalisation sans consentement en psychiatrie : analyse et déterminants de la variabilité territoriale en 2010. Revue Française des Affaires Sociales, 253-273.

Coldefy, M., \& Salines, E. (2004). Les secteurs de psychiatrie en 2000: Evolutions et disparités, Etudes \& Résultats, N.342, 1-11.

Emons, B., Haussleiter, I. S., Kalthoff, J., Schramm, A., Hoffmann, K., Jendreyschak, J., ... Iles, F. (2014). Impact of social-psychiatric services and psychiatric clinics on involuntary admissions. International Journal of Social Psychiatry, 6, 672-680. https://doi.org/10.1177/0020764013511794

Endicott, J., Spitzer, R. L., Fleiss, J. L., \& Cohen, J. (1976). The Global Assessment Scale: A procedure for measuring overall severity of psychiatric disturbance. Archives of General Psychiatry, 33, 766-771.

Fleiss, J. L. (1986). Reliability of measurement. New York: J. Wiley and Sons

Fermanian, J. (1984). Measuring agreement between 2 observers: a quantitative case. Revue d'Epidémiologie et de Santé Publique, 32, 408-413.

Gandré, C., Gervaix, J., Thillard, J., Macé, J. M., Roelandt, J. L., \& Chevreul, K. (2007a). Involuntary psychiatric admissions and development of psychiatric services as an alternative to full-time hospitalization in France. Psychiatric Services. https://doi.org/10.1176/appi.ps.201600453

Gandré, C., Gervaix, J., Thillard, J., Macé, J. M., Roelandt, J. L., \& Chevreul, K. (2007b). The development of psychiatric services providing an alternative to full-time hospitalization is associated with shorter length of stay in French public psychiatry, International Journal of Environmental Research and Public Health, 14(3), 325. https://doi.org/10.3390/ijerph14030325

Gourevitch, M. (2005). Le traitement en France du délinquant présentant des troubles mentaux. Perspectives Psy, $44,178-181$.

Guzzetta, F., Miglio, R., Santone, G., Picardi, A., Norcio, B., Bracco, R., \& De Girolamo, G. (2010). First-ever admitted psychiatric inpatients in Italy: Clinical characteristics and reasons contributing to admission: Findings from a national survey. Psychiatry Research, 176, 62-68. https://doi.org/10.1016/j.psychres.2008.11.005 
Hustoft, K., Larsen, T. K., Auestad, B., Joa, I., Johannessen, J. O., \& Ruud, T. (2013). Predictors of involuntary hospitalizations to acute psychiatry. International Journal of Law Psychiatry, 36, 136-143. https://doi.org/10.1016/j.ijlp.2013.01.006

Jaeger, S., Pfiffner, C., Weiser, P., Längle, G., Croisssant, D., Schepp, W., ... Steinert, T. (2013). Long-Term Effects of Involuntary Hospitalization on Medication Adherence, Treatment Engagement and Perception of $\begin{array}{llll}\text { Coercion. Social Psychiatry and Psychiatric Epidemiology, 48, 1787-1796. } & \text {. }\end{array}$ https://doi.org/10.1007/s00127-013-0687-x

Joubert F., Hechinger, M., Chevallier, V., \& Marescaux, C. (2016). Hospitalisations sans consentement en psychiatrie : analyse comparative chez les personnes résidant ou non en zones urbaines sensibles. Santé Publique, 28, 61-69. https://doi.org/10.3917/spub.161.0061

Krug, E. G., Dahlberg, L. L., Mercy, J. A., Zwi, A., \& Lozano-Ascencio, R. (2002). Rapport mondial sur la violence et la santé. Genève : OMS.

Rosca, P., Bauer, A., Grinshpoon, A., Khawaled, R., Mester, R., \& Ponizovsky, A. M. (2006). Rehospitalizations among psychiatric patients whose first admission was involuntary: a 10-year follow-up. Israel Journal of Psychiatry and Relates Sciences, 43, 5-64.

Rüsch, N., Müller, M., Lay, B., Corrigan, P. W., Zahn, R., Schönenbersg, T., ... Rössler, W. (2014). Emotional Reactions to Involuntary Psychiatric Hospitalization and Stigma-Related Stress among People with Mental Illness. European Archives of Psychiatry and Clinical Neuroscience, 264, 3-43. https://doi.org/10.1007/s00406-013-0412-5

Trojak, B. (2006). Hospitalisation sans consentement : faut-il en définir les indicateurs? Mémoire de Master en éthique médicale, U. Paris V.

Van der Post, L., Schoevers, R., Koppelmans, V., Visch, I., Bernardt, C., Mulder, N., ... Dekker,J. (2008). The Amsterdam Studies of Acute Psychiatry I(ASAP-I) A prospective cohort study of determinants and outcome of coercive versus voluntary treatment interventions in a metropolitan area. BMC Psychiatry, 14, 8-35. https://doi.org/10.1186/1471-244X-8-35

Wang, J-P., Chiu, C. C., Yang, T. H., Liu, T. H., Wu, C. Y., \& Chou, P. (2015). The Low Proportion and Associated Factors of Involuntary Admission in the Psychiatric Emergency Service in Taiwan. PLOS ONE, 10(6), e0129204. https://dx.doi.org/10.1371\%2Fjournal.pone.0129204

Weich, S., McBride, O., Twigg, L., Keown, P., Cyhlarova, E., Crepaz-Keay, D. .... Bhui, K. (2014). Variation in compulsory psychiatric inpatient admission in England: A cross-sectional, multilevel analysis. Health Service Delivery, 49, 1-90. http://dx.crossref.org/10.3310/hsdr02490

Wheeler, A., Robinson, E., \& Robinson, G. (2005). Admissions to acute psychiatric inpatient services in Auckland, New Zealand: a demographic and diagnostic review. New Zealand Medical Journal, 118, 1226

Workin, R. J., Friedman, L. C., Telschow, R. L., Grant, K. D., Moffic, H. S., \& Sloan, V. J. (1990). The longitudinal use of the global assessment scale in multiple-rater situations. Community Mental Health Journal, 26, 335-344.

\section{Notes}

Note 1. Fédération Régionale de Recherche en Santé Mentale, Association pour l'Evaluation de la Formation Continue des Psychiatres, Association Nationale pour la Clinique, la Recherche et l'Enseignement en Psychiatrie.

Note 2. For an illustration of the debate between Justice and Mental Health, see Gourevitch (2005)

Note 3. The study started before the 5th July 2011 Law, i.e. before "psychiatric care on decision by the state representative" replaced compulsory hospitalization". However, for the sake of simplicity, we will use the general term compulsory hospitalization to refer to both systems.

Note 4. Sources: The French general health department - activity reports from the psychiatric hospitalization departmental commissions - 2007.

Note 5. Source: The French agency for hospital information processing (ATIH).

Note 6. One hundred and twenty commitment documents were selected at random and divided into 3 groups of 40, coded independently by 3 trained pairs (a psychologist and a psychiatrist). The inter-rater agreement, 
assessed by the intra-class coefficient, was respectively $.86, .92$, and .74 . An intra-class coefficient between 0.7 and .9 is considered as good, and above 0.9 is excellent $[27,28]$, so the inter-coding reliability was at least always good.

Note 7. Article D398 amended by Decree N98-1099 of December 8th 1998 - art.90 JORF 9th December 1998: "prisoners suffering from mental disorders as stipulated in article L.342 of the Public Health Code, cannot be detained in prison. In light of a detailed medical certificate and in accordance with the law in force, it is up to the Prefect's authority to decide, at their earliest convenience, on their involuntary hospitalization in a health institution, empowered by article L.331 of the Public Health Code. The rule stipulated in the second paragraph of article D.394 concerning their custody by police staff during their hospitalization does not apply"

Note 8. Article 122-1 of the penal code: "Any person having suffered, at the time of the deeds, from psychiatric or neuro-psychiatric disorders, mentioned in article L.342 of the Public Health Code, thus affecting their judgement and the control of their deeds cannot be held penally responsible. Any person having suffered, at the time of the deeds, of psychiatric or neuro-psychiatric disorders altering their judgement and the control of their deeds remains punishable. However, the jurisdiction takes this circumstance into account, when it determines the sentence and decides on its settlement".

Note 9. The percentages of sectors with at least one local health Council are respectively $2.44,13.33$, and 31.58 . The 2 by 2 comparisons reveal that the proportion of local health Councils only differs between the low and the high rate. The percentages of those with at least one shelter and social insertion center are 53.6, 70 and 84.2. No 2 by 2 comparison is significant.

\section{Appendix 1}

\section{Territorial landscape: list of variables}

\section{Sources (collected by IRDES):}

- Annual Statistics of the institutions (SAE in French), survey produced by the DREES for 2011, data provided by the institutions with no statistical adjustment

- Population census (INSEE, 2010)

- Data collected from the WHO CC on the sectors under study and the presence of CLSM

- Data from the national database for inter-system information in the French national insurance produced by the national authority for workers' health insurance, 2010

- Data from the Ministry of Justice (2011)

- Data from the permanent Equipment database (INSEE, 2011)

\section{Demography of the sector}

\section{Social demographic data}

- Total population

o Breakdown (in \%) population age: 0 - 17 years, $18-64$ years, over 65

o Breakdown (in \%) men - women

o Number of single-person households

o Proportion of isolated people

o Proportion of working people from 15 to 64 years old

o Unemployment rate

- Average weighted by the population of the household mean income per consumption unit per commune (administrative subdivision below the département) (in Euros)

\section{Description of the psychiatric territory}

- Surface area of the general psychiatry sector (in $\mathrm{km}^{2}$ )

o Institution to which the general psychiatry sector is attached

o Type of institution to which the general psychiatry sector is attached

o Group of general psychiatry sectors attached to the same institution 
- Administrative Region

o Number of local mental health Councils

○ Mean distance weighted by the population to the nearest unit for difficult patients (in minutes)

\section{Description of the judiciary territory}

o Presence or not of a prison

o Mean distance weighted by the population to the nearest prison (in minutes)

o Density of prisoners per 100,000 inhabitants

- Number of police stations

- Mean distance weighted by the population to the nearest police station (in minutes)

o Presence or not of a Préfecture

o Mean distance weighted by the population to the nearest Préfecture (in minutes)

\section{Care offer}

\section{Care offer in general medicine}

Description of "files actives" (hereafter "active file") and hospital stays

o Average duration of hospitalisation

Institutions/ Facilities / Services

o Presence or not of an emergency reception facility

o Mean distance weighted by the population to the nearest emergency reception facility (in minutes)

o Number of shelters and social insertion centres

Staff

o Density of general practitioners, irrespective of type of practice, working on 31/10/2010 per 100000 inhabitants

\section{Care offer in psychiatry}

Description of active file and hospital stays

o Density of full-time hospitalization beds in public institutions located in communes in the mega-sector per 100,000 inhabitants

o Density of full-time hospitalization beds in private, profit-making institutions, located in communes in the mega-sector per 100,000 inhabitants

o Density of full-time hospitalization beds in private, non-profit-making institutions located in communes in the mega-sector per 100,000 inhabitants

o Density of patients examined at least once in the year (total active file) in general psychiatry per100,000 inhabitants

o Number of patients examined at least once in the year (total active file) in general psychiatry broken down into sectors depending on the population

o Average number of patients examined at least once in the year (total active file) in general psychiatry by a salaried psychiatrist

o Density of patients examined at least once in the year in ambulatory mode exclusively (exclusively ambulatory active file) in general psychiatry per 100,000 habitants

o Number of patients examined at least once in the year in ambulatory mode exclusively (exclusively ambulatory active file) in general psychiatry, broken down into sectors depending on the population

o Density of patients hospitalized full-time at least once in the year (Full-time hospitalized active file) in general psychiatry per 100,000 inhabitants

o Number of patients hospitalized at least once in the year (Full-time hospitalized active file) in general psychiatry, broken down into sectors depending on the population

o Rate of resort to voluntary hospitalization per 100,000 inhabitants 
O Rate of resort to hospitalization on request from a third party per 100,000 inhabitants

- Rate of occupation of beds in general psychiatry

o Number of days of full-time complete hospitalization in psychiatry (not including child--psychiatry)*Total active file in psychiatry (not including child psychiatry)*

o Active file of people hospitalized full-time in psychiatry (not including child--psychiatry)*

o Rate of re-hospitalization in psychiatry (not including child--psychiatry)*

Institutions / Facilities / Services

o Presence or not of a unit for difficult patients

o Year of opening of the unit for difficult patients

o Presence or not of a specialized mobile team (circular 521 of 23/11/2005)

- Presence or not of a mobile team specialized in precariousness

o Presence or not of a crisis reception unit and an emergency reception unit

o Density of the medical/psychological facilities or consultation units in psychiatric departments of general psychiatry per 100,000 inhabitants

o Psychiatric care offer

o Density of reception facilities in part-time therapeutic reception units and workshops per 100,000 inhabitants

o Therapy in general psychiatry

o Density of beds for complete hospitalization (including hospitalization during the week) in general psychiatry per 100,000 inhabitants

o Density of beds or places providing an alternative to full-time hospitalization per 100,000 inhabitants

o Density of part-time hospitalization places in general psychiatry per 100,000 inhabitants

o Density of full-time hospitalization beds in specialized public institutions located in communes in the mega-sector per 100,000 inhabitants

○ Number of full-time beds in in psychiatry (not including child--psychiatry)*

o Density of practising psychiatrists on 31.12 .2010 per 100,000 inhabitants

o Density of salaried psychiatrists in general psychiatry (equivalent full-time) per 100,000 inhabitants

o Proportion of salaried psychiatrists not working full-time in a hospitalization unit out of the total number of salaried psychiatrists in general psychiatry

o Density of non-psychiatric doctors salaried in general psychiatry (equivalent full-time) per 100000 inhabitants

o Proportion of non-psychiatric doctors salaried and not working full-time in a hospitalization unit, out of the total number of non-psychiatry doctors in general psychiatry

o Density of nurses and health unit executives in general psychiatry (equivalent full-time) per 100000 inhabitants

o Proportion of nurses and health unit executives not working full-time in hospitalization units out of the number of nurses and executives in general psychiatry

o Density of auxiliary nurses in general psychiatry units (equivalent full-time) per 100,000 inhabitants

o Proportion of auxiliary nurses in health units not working full-time in hospitalization units, out of the number of auxiliary nurses in general psychiatry units

o Density of psychologists in general psychiatry units (equivalent full-time) per 100,000 inhabitants

o Proportion of psychologists in health units not working full-time in hospitalization units, out of the total number of psychologists in general psychiatry units

o Density of rehabilitation staff in general psychiatry units (equivalent full-time) per 100,000 inhabitants 
o Proportion of rehabilitation staff in health units not working full-time in hospitalization units, out of the total number of rehabilitation staff in general psychiatry units

o Density of educational and social staff in general psychiatry units (equivalent full-time) per 100, 000 inhabitants

o Proportion of educational and social staff in health units not working full-time in hospitalization units, out of the total number of educational and social staff in general psychiatry units

o Equivalent full-time hospitalization (full-time) in psychiatry (not including child--psychiatry)*

o Equivalent full-time (not including full-time) in psychiatry (not including child--psychiatry)*

o Total equivalent full-time in psychiatry (not including child--psychiatry)*

o Percentage of equivalent full-time (not including full-time) out of the total number in psychiatry (not including child--psychiatry)*

* Treatment provision variables, added after request to the French medical information department

\section{Copyrights}

Copyright for this article is retained by the author(s), with first publication rights granted to the journal.

This is an open-access article distributed under the terms and conditions of the Creative Commons Attribution license (http://creativecommons.org/licenses/by/4.0/). 